\title{
ВЛИЯНИЕ ШОКОВОГО МЕТАМОРФИЗМА НА СОСТАВ И СТРОЕНИЕ ЦИРКОНА В МАССИВЕ ЯРВА-ВАРАКА КОЛЬСКОГО ПОЛУОСТРОВА
}

\author{
Каулина Т.В. ${ }^{1}$, Нерович Л.И. ${ }^{1}$ Шиловских В.В. ${ }^{2}$ \\ ${ }^{1}$ Геологический институт КНЦ РАН, Anamumbl, kaulina@geoksc.apatity.ru \\ ${ }^{2}$ СПбГУ, Ресурсный центр «Геомодель»
}

Расслоенный массив Ярва-варака Мончегорского рудного района расположен в 12 км к С3 от г. Мончегорска и представляет собою интрузивное тело неправильной формы размером $1.7 \times 2.2$ км в плане и мощностью до 2 км, вмещающими породами являются глиноземистые гнейсы кольской серии. В составе интрузии принимают участие породы от основного до кислого состава. Преобладают гранофировые гиперстеновые диориты, широко представлены кварцевые диориты и гранофировые нориты, чья роль увеличивается с глубиной.

Результаты изучения массива Ярва-варака [3] показали, что по присутствию значительной доли гранофира во всех породах по разрезу интрузива, по петрографическому и геохимическому составу пород, сопоставимой мощности магматического комплекса ( 2000 м) и наличию брекчии в основании он имеет сходство с крупнейшим $\mathrm{Cu}-\mathrm{Ni}$ месторождением Садбери, для которого установлена генетическая связь с метеоритным ударом $[7,4]$. Эти данные стимулировали изучение циркона из пород массива Ярва-варака, поскольку циркон может сохранять признаки ударного метаморфизма, даже пройдя в дальнейшем через условия гранулитовой фации, что позволяет использовать его как индикатор ударного метаморфизма при изучении древних, глубоко эродированных и метаморфически преобразованных импактных структур $[8,9]$.

В последние годы роль метеоритных ударов в эволюции земной коры широко обсуждается в научной литературе (например, $[6,1])$, тем не менее, специальных исследований, направленных на идентификацию древних метеоритных кратеров на российской территории Балтийского щита не проводилось, хотя сильнейшие метеоритные бомбардировки Земли были именно в докембрии.

Ранее нами был изучен циркон из гранофировых норитов массива Ярва-варака методом рамановской спектроскопии [2], которая представляет собой экспрессный и точный метод анализа циркона на микро-уровне. Кристаллы циркона показали вариации рамановских спектров для разных областей кристаллов: от типичного для циркона рамановского спектра в центре кристаллов до полного отсутствия спектральных линий в периферических зонах и каймах. При этом в минеральных включениях силлиманита и плагиоклаза, расположенных в каймах циркона, рамановские пики также отсутствуют. С нашей точки зрения, эти вариации спектров могут быть связаны с преобразованием кристаллического циркона (и минеральных включений в нем) в диаплектовые стекла вследствие ударного метаморфизма [2].

В настоящей статье мы представляем результаты изучения химического состава циркона из гранофировых норитов массива Ярва-варака, для тех же зерен, которые ранее были изучены КР-методом.

\section{Внутреннее строение и химический состав циркона}

Циркон, выделенный из гранофировых норитов, представлен прозрачными светлокоричневыми, желтыми и бесцветными короткопризматическими зернами и их фрагментами. Циркон содержит многочисленные включения состава $\mathrm{Al}, \mathrm{Si}, \mathrm{O}$, что указывает на полиморфную модификацию: андалузит-силлиманит-кианит; а также состава $\mathrm{Si}, \mathrm{Al}, \mathrm{Na}, \mathrm{Ca}, \mathrm{O}$, предполагая минералы группы полевых шпатов. Поскольку вмещающими породами для гранофировых норитов являются глиноземистые гнейсы кольской серии, наиболее вероятно, что изученный циркон является ксеногенным и захвачен именно из глиноземных гнейсов.

Изображение циркона в обратно-рассеянных электронах выявило сложное строение зерен с темными внутренними участками (ядрами) разной формы и вероятно разного генезиса, поскольку глиноземистые гнейсы являются парапородами, и светлой в BSE широкой каймой без четко выраженной структуры (рис. 1). В режиме катодолюминесценции каймы темные и практически не люминесцируют. Некоторые ядра имеют тонкую зональность и плавные переходы к краевым частям (кайме) (рис. 1 б, г, д), поэтому можно предположить, что и центр и кайма - это одна генерация циркона. В некоторых зернах граница между ядром и каймой резкая (рис. 1 е), что предполагает раз- 

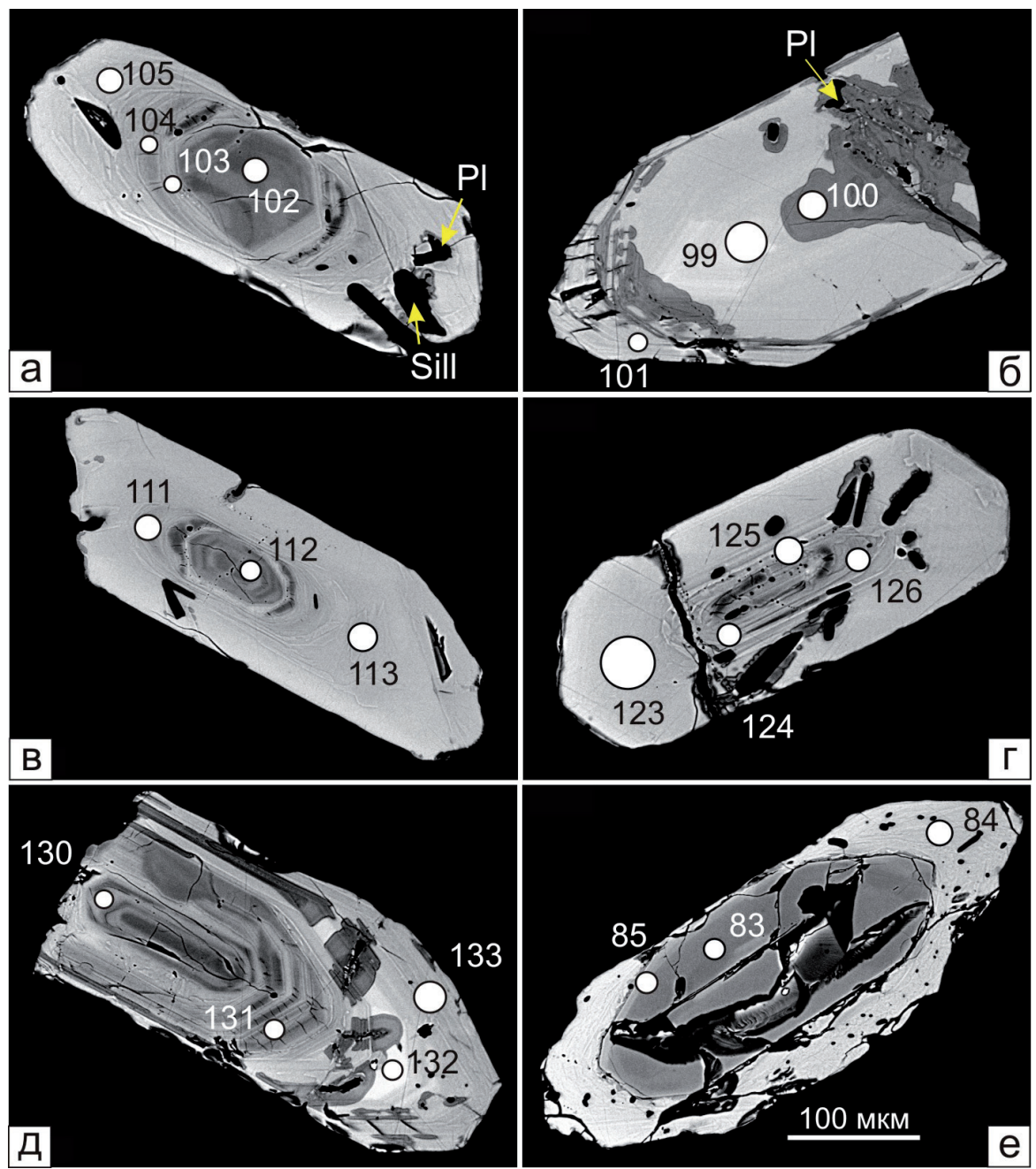

Рис. 1. Вид циркона в обратно-рассеянных электронах с точками микрозондового анализа.

новременное образование ядра и каймы. В нескольких зернах видны более поздние наложенные на кайму процессы изменения - темные криволинейные участки вдоль трещин и вокруг включений (рис. 1 б, д).

Микроэлементный состав отдельных доменов циркона определялся на сканирующем электронным микроскопе Hitachi S-3400N с энергодисперсионным спектрометром Oxford Instruments $\mathrm{X}-\mathrm{Max} 20$ в ресурсном центре «Геомодель» (СПбГУ). Обработка спектров производилась автоматически при помощи программного пакета AzTec Energy с использованием методики TrueQ. При съемке использованы следующие установки: ускоряющее напряжение 20 кВ, ток зонда 1.5 нА, время накопления спектра в точке - 30 секунд в точечном режиме. Количественный расчет спектров проведен с использованием стандартных образцов природных и синтетических соединений.

Содержания всех элементов в ядрах и каймах изученных зерен циркона перекрываются. Тем не менее, нужно отметить, что ядра в среднем содержат больше $\mathrm{Th}$, иногда $\mathrm{Fe}$ и $\mathrm{Yb}$, а каймы содержат больше U и Hf (табл. 1). Возможно, выравнивание состава также связано с импактными процессами, когда высокая температура шокового метаморфизма ускорила диффузию элементов.

Полученные данные, вместе с рамановской спектроскопией показывают, что импактные события имели место после образования кайм в цирконе. U-Pb возраст Grt-Bt и Sill-Grt-Bt гнейсов кольской серии в Мончегорском районе составляет $2832 \pm 11$ млн. лет, U-Pb возраст бадделеита из диоритов Ярва-вараки определен в $2496 \pm 9$ млн. лет [5]. То есть, метеоритный удар мог произойти около 2.5 млрд. лет назад; ударная волна вызвала аморфизацию циркона в глиноземистых гнейсах (внутренние части кристаллов экранировались каймами и сохранили свою структуру), фрагменты которых затем были захвачены (образовавшимся при импакте?) расплавом. 
Таблица 1. Состав циркона из гранофировых норитов.

\begin{tabular}{|c|c|c|c|c|c|c|c|c|c|c|c|}
\hline \multicolumn{10}{|c|}{ Элемент, масс.\% } \\
\hline $\mathrm{N}$ тчк & домен & $\mathrm{Al}$ & $\mathrm{P}$ & $\mathrm{Ca}$ & $\mathrm{Fe}$ & $\mathrm{Zr}$ & $\mathrm{Yb}$ & $\mathrm{Hf}$ & $\mathrm{Zr} / \mathrm{Hf}$ & $\mathrm{Th}$ & $\mathrm{U}$ \\
\hline 102 & ядро & & 0.47 & & 0.05 & 48.46 & 0.06 & 0.70 & 69 & 0.09 & \\
\hline 103 & ядро & 0.01 & 0.46 & & & 47.79 & 0.12 & 1.22 & 39 & & 0.13 \\
\hline 104 & кайма & & 0.53 & & 0.02 & 48.21 & & 1.39 & 35 & & 0.04 \\
\hline 105 & кайма & & 0.4 & 0.02 & 0.04 & 48.38 & 0.08 & 2.21 & 22 & & 0.04 \\
\hline 99 & кайма & & 0.47 & 0.03 & & 44.46 & & 1.14 & 39 & & 1.2 \\
\hline 100 & измен & 0.04 & 0.56 & & 0.03 & 43.97 & & 1.44 & 31 & 0.16 & 0.75 \\
\hline 101 & кайма & 0.02 & 0.49 & 0.02 & 0.02 & 45.46 & 0.09 & 1.34 & 34 & 0.02 & 0.04 \\
\hline 111 & кайма & & 0.4 & & 0.04 & 46.72 & & 1.19 & 39 & 0.06 & 0.02 \\
\hline 112 & ядро & & 0.55 & 0.05 & & 46.71 & 0.23 & 0.96 & 49 & 0.21 & \\
\hline 113 & кайма & 0.01 & 0.33 & 0.02 & & 46.82 & & 1.75 & 27 & 0.11 & \\
\hline 123 & кайма & 0.01 & 0.45 & & 0.06 & 46.73 & 0.03 & 2.14 & 22 & & 0.14 \\
\hline 124 & ядро & 0.01 & 0.37 & & 0.02 & 47.00 & 0.04 & 1.48 & 32 & 0.06 & \\
\hline 125 & ядро & 0.05 & 0.44 & 0.01 & 0.03 & 46.85 & & 1.07 & 44 & 0.07 & 0.05 \\
\hline 126 & ядро & & 0.51 & & 0.04 & 47.18 & 0.21 & 1.67 & 28 & & 0.06 \\
\hline 130 & ядро & & 0.41 & & & 48.24 & 0.08 & 0.90 & 54 & 0.11 & 0.06 \\
\hline 131 & ядро & 0.01 & 0.41 & 0.01 & & 47.19 & & 1.05 & 45 & & 0.03 \\
\hline 132 & кайма & & 0.51 & 0.04 & 0.04 & 45.40 & 0.14 & 1.53 & 30 & & 1.29 \\
\hline 133 & кайма & 0.04 & 0.40 & & 0.07 & 48.23 & 0.01 & 1.42 & 34 & & 0.14 \\
\hline 83 & ядро & 0.04 & 0.44 & 0.05 & 0.06 & 47.37 & & 0.84 & 56 & & 0.03 \\
\hline 84 & кайма & 0.03 & 0.48 & & 0.06 & 48.10 & 0.25 & 1.15 & 42 & 0.05 & 0.03 \\
\hline 85 & ядро & 0.02 & 0.30 & & 0.12 & 47.52 & 0.04 & 0.98 & 48 & 0.16 & \\
\hline
\end{tabular}

Номера точек в таблице соответствуют номерам анализов на рис. 1.

\section{Благодарности}

Исследования выполнены в рамках Госзадания ГИ КНЦ РАН при поддержке программы президиума РАН № 19 «Фундаментальные проблемы геолого-геофизического изучения литосферных процессов».

\section{Литература}

1. Глуховский М. З., Кузьмин М.И. Котуйканская кольцевая структура: возможное свидетельство масштабного импактного события на севере Сибирского кратона // Геология и геофизика. 2013. Т. 54. № 1. С 3-26.

2. Каулина Т.В., Нерович Л.И., Бочаров В.Н., Лялина Л.М., Ильченко В.Л., Кунаккузин Е.Л., Касаткин И.А. Рамановская спектроскопия импактного циркона из расслоенного массива Ярва-варака (Мончегорский рудный район, Кольский полуостров) // Вестник МГТУ. 2017. Т. 20, № 1/1. С. 72-82. DOI:10.21443/1560-9278-2017-20-1/1-72-82.

3. Нерович Л.И., Баянова Т.Б., Кунаккузин Е.Л., Базай А.В., Некипелов Д.А. Новые результаты геологопетрографического и геохимического изучения расслоенного массива Ярва-варака, Мончегорский рудный район // Тр. Ферсмановской научной сесии ГИ КНЦ РАН. 2015. Т. 12. С. 141-146.

4. Налдретт А. Дж. Магматические сульфидные месторождения медно-никелевых и платинометальных руд. СПб.: Изд-во СПбГУ, 2003. 487 с.

5. Смолькин В.Ф., Федотов Ж.А., Нерадовский Ю.Н., Баянова Т.Б., Борисова В.В., Глазнев В.Н. Расслоенные интрузии Мончегорского рудного района: петрология, оруденение, изотопия, глубинное строение. Ч. 1. Апатиты: КНЦ РАН, 2004. 177 с.

6. Glikson A.Y. and Vickers J. Asteroid impact connections of crustal evolution // Australian Journal of Earth Sciences. 2010. V. 57. P. 79-95.

7. Grieve R. A. F. An impact model for the Sudbury structure // Proceedings of the Sudbury-Noril'sk Symposium: Ontario Geological Survey Special Volume. 1994. V. 5. P. 119-132.

8. Gucsik A., Koeberl C., Brandstätter F., Reimold W.U., Libowitzky E. Cathodoluminescence, electron microscopy, and Raman spectroscopy of experimentally shock-metamorphosed zircon // Earth and Planetary Science Letters. 2002. V. 202. P. 495-509.

9. Gucsik A., Zhang M., Koeberl C., Salje E.K.H., Redfern S.A.T., Pruneda J.M. Infrared and Raman spectra of $\mathrm{ZrSiO}_{4}$ experimentally shocked at high pressures // Mineral. Mag. 2004. V. 68. P. 801-811. 